\title{
ACUTE AIRWAY OBSTRUCTION DUE TO OEDEMA OF THE LARYNX FOLLOWING ANTIMONY THERAPY IN MUCOSAL LEISHMANIASIS
}

\author{
J. M. L. Costa, E. M. Netto and P. D. Marsden
}

Torres $^{3}$ was the first to mention this complication. We occasionally see patients with tracheostomy scars in the neck who give a history of an emergency operation after beginning drug therapy ${ }^{2}$. We wish to record a patient here whom we were able to observe at first hand.

Case Number LTB 491. A mulatto male from Altamira farm, Jaguaguara, Bahia, who for five years had occasional nasal obstruction, pain, and epistaxis. For two years he had noticed an anterior septal ulceration. He had taken glucantime 1 ampoule per day for a total of 24 days $(8 \mathrm{mg} \mathrm{Sb} / \mathrm{kg} /$ day $)$ at irregular intervals without side effects. Recently his voice had become hoarse.

On examination he had two skin scars of cutaneous leishmaniasis acquired 10 years previously. One on the right arm measured $20-15 \mathrm{~mm}$ and that on the left leg 15-10 millimetres. His nose was a little oedematous and the septum hyperemic and infiltrated with an ulcer on the anterior part of the septum with crusted borders. There were minute granulomas on the hard palate. The vocal cords could not be visualised due to oedema of the epiglottis.

The leishmanin skin test was positive at $7 \mathrm{~mm}$ and the indirect immunofluorescent test positive at a $1 / 20$ dilution. A biopsy was taken from the nose which showed a histology compatible with leishmaniasis although no amastigotes were seen in the section nor Giemsa stained smears. Facilities were not available for culture or hamster inoculation.

Therapy was begun with 3 ampoules of glucantime by slow intravenous injection $(24 \mathrm{mg} \mathrm{Sb} / \mathrm{kg} / \mathrm{day})$. Three hours after the first injection he felt poorly and had fever, sweating and progressive difficulty in breathing with cyanosis. He was rushed to the emergency room in Jaguaguara hospital where an emergency tracheostomy was performed with uneventful iecovery. The antimony dose was dropped to one ampoule $(8 \mathrm{mg} \mathrm{Sb} / \mathrm{kg} /$ day) for 10 days without side effects and a second similar course was given 3 months later. At six months he is asymptomatic but still under observation.

While only a small number of patients with laryngeal disease develop this complication a tracheostomy set should be available during the early phase of treatment. The laryngeal oedema is similar to the oedema and haemorrhage sometimes seen in skin lesions and seems to be a type of Jarisch Herheimer reaction. ${ }^{2}$ Our patient showed the clinical features of a Jarisch Herxheimer reaction with fever, lesion swelling and signs of cardiovascular shock. Although this reaction was initially described in syphilis it occurs in several other infectious diseases and is thought to be the result of the release of endotoxins from dying parasites ${ }^{1}$. We have seen it with Amphotericin B therapy so it is not a drug specific effect. Probably the previous antimony treatment our patient received did not influence the subsequent airway obstruction. It is more likely that the high single dose of antimony was the aggravating factor. This suggests that high local tissue antimony levels are rapidly achieved and effective against the parasite. Simply stopping the drug results in resolution in $\mathbf{4 8}$ hours and we have never seen a recurrence on recommencing therapy. Corticosteroids might be indicated to reduce oedema but we have never used them to date.

Another consideration in that this man was treated with a glucantime preparation which has produced side effects (fever, local pain on injection) in some patients. In our laboratories the osmolarity of this glucantime provided by the Ministry of Health is abnormal when compared with the standard Rhodia product. This glucantime could have aggravated the constitutional effects observed in our patient.

\section{REFERENCES}

1. Bryceson ADM. Clinical pathology of Jarisch Herxheimer reaction. Journal of Infectious Diseases 133: 696-704, 1976.

2. Rocha RAA, Sampaio RN, Guerra M, Magalhàes AV, Cuba CC, Barreto AC, Marsden PD. Apparent glucantime failure in five patients with mucocutaneous leishmaniasis. Journal of Tropical Medicine and Hygiene 83:131-139, 1980.

3. Torres O. A leishmaniose na Bahia. Arquivos Brasileiros de Medicina 7:373-425, 1920.

Núcleo de Medicina Tropical e Nutrição, Universidade de Brasilia, 70910 Brasilia, DF, Brasil.

Recebido para publicação em 12/1/1986. 